\title{
Campylobacter colonization is not associated with proventricular dilatation disease in psittacines
}

This article was published in the following Dove Press journal:

Veterinary Medicine: Research and Reports

3 August 2017

Number of times this article has been viewed

\author{
Holden Bulbow \\ Jing Wu \\ Debra Turner \\ Michael McEntire \\ lan Tizard \\ Schubot Exotic Bird Health \\ Center, Department of Veterinary \\ Pathobiology, College of Veterinary \\ Medicine, Texas A\&M University, \\ College Station, TX, USA
}

\begin{abstract}
Psittacine proventricular dilatation disease (PDD) is a neurological disease caused by parrot bornaviruses. A competing theory suggests that intestinal colonization by Campylobacter species may also be a potential cause of PDD or that their presence may be required for disease development. This theory proposes that PDD results from the activities of antiganglioside antibodies on enteric neurons in a manner similar to the pathogenesis of Guillain-Barré syndrome in humans. We therefore cultured feces from domestic chickens as well as from multiple parrot species to determine whether Campylobacter spp. could be detected in the latter. We failed to detect Campylobacter in a flock of cockatiels known to be highly susceptible to experimental parrot bornavirus-induced PDD. Even in naturally infected psittacines suffering from clinical PDD, no Campylobacter species were detected. Conversely, Campylobacter was readily cultured from domestic poultry samples and confirmed by using matrix-associated laser desorption ionization mass spectroscopy/real-time polymerase chain reaction. We conclude that not only are Campylobacter infections of psittacines uncommon, but also that infection by Campylobacter species is not related to the etiology of PDD.
\end{abstract}

Keywords: bornavirus, campylobacter, proventricular dilatation disease, parrots, chickens

\section{Introduction}

Proventricular dilatation disease (PDD) is a neurologic disease of parrots. Clinically, it presents as gastrointestinal dysfunction characterized by anorexia, crop stasis, and a massively dilated proventriculus. These effects appear to be a consequence of the destruction of enteric neurons. ${ }^{1-3}$ The sole confirmed causative agent of psittacine PDD is parrot bornavirus $(\mathrm{PaBV})$. Proventricular dilatation attributable to other bornaviruses has been observed in geese and canaries., ${ }^{3,4}$ PDD does not develop in the absence of PaBV, and Koch's postulates have been repeatedly fulfilled linking PaBV to the development of PDD. ${ }^{5,6}$ Thus, PDD is readily and consistently induced in cockatiels (Nymphicus hollandicus) by intramuscular challenge with tissue cultured PaBV.

There is a competing theory that attributes PDD to the development of autoantibodies against gangliosides and suggests that PDD is a form of Gullain-Barré syndrome (GBS). ${ }^{7,8}$

Many cases of GBS in humans appear to be induced by the development of crossreacting antibodies to enteric Campylobacter jejuni. The proposed pathophysiology suggests that PDD is mediated by immune responses to the lipo-oligosaccharide of C. jejuni. These exhibit molecular mimicry to gangliosides expressed on neurons, especially at the nodes of Ranvier. ${ }^{9-11}$ As a result, antibodies directed against Campylobacter antigens also target gangliosides within the myelin sheath, and these antibodies
Correspondence: lan Tizard Schubot Exotic Bird Health Center, Department of Veterinary Pathobiology, College of Veterinary Medicine, Texas A\&M University, College Station, Texas 77843-4467, USA

Tel +l 9798454276

Email itizard@crm.tamu.edu
Veterinary Medicine: Research and Reports 20I 7:8 37-40

37 (c) (i) (5) 2017 Bubbow et al. This work is published and licensed by Dove Medical Press Limited. The full terms of this license are available at https://www.dovepress.com/terms. (c) BY you hereby accept the Terms. Non-commercial uses of the work are permitted without any further permission from Dove Medical Press Limited, provided the work is properly attributed. For permission for commercial use of this work, please see paragraphs 4.2 and 5 of our Terms (https://www.dovepress.com/terms.php) 
will then cause demyelination and impaired nerve function. This impairment, it is suggested, would result in the gastrointestinal symptoms associated with PDD.

This study was therefore designed to determine whether Campylobacter was present in the intestinal microbiota of healthy PDD-susceptible and resistant psittacines as well as birds suffering from clinical PDD.

Members of the Campylobacter genus are enteric, helical bacteria that are microaerophilic, resistant to cephalosporin, oxidase positive, and, for the most part, catalase positive. $C$. jejuni has a natural reservoir in chickens, and some passerine species. It is widespread in wild birds, especially feral pigeons, crows, and waterfowl. ${ }^{12-17}$ It is a significant cause of human food poisoning due to its high prevalence in commercial poultry. C. jejuni prevalence ranges from $45 \%$ at the flock level and $93 \%$ at the farm level. ${ }^{18}$ It can thus be considered a component of the normal chicken microbiota. Chicken fecal samples therefore served as positive controls in the search for Campylobacter.

\section{Materials and methods}

Sixty three avian fecal samples from 52 birds were cultured to test for the presence of Campylobacter spp. Of these, 26 samples were from chickens and 27 from psittacines. Aviary birds that were tested included 6 Monk parakeets (Myiopsitta monachus), 5 cockatiels (Nymphicus hollandicus), 12 macaw (Ara sp) species (six twice), six from African gray parrots (Psittacus erithracus) (three twice), two from Amazon parrots sp (one twice), and two from a blue-headed parrot (Pionus menstruus). All these birds were housed in the Texas A\&M Avian Health Complex. Four single parrot samples were obtained from birds admitted to the Texas A\&M Veterinary Medical Teaching Hospital for diagnosis and treatment of suspected PDD. These included one each of a macaw, African gray, Amazon sp, and sulfur-crested cockatoo (Cacatua galerita). This study was performed under a protocol approved by Texas A\&M University Animal Use and Care Committee: IACUC 2014-0169.

Samples were collected using sterile swabs and refrigerated for transfer to the laboratory. Samples were plated shortly thereafter. Two types of selective plate media were used for culturing the fecal samples: Campy BBL w/10\% sheep blood (Becton Dickinson, \# 221728, Franklin Lakes, NJ, USA) and Campy-Cefex (Becton Dickinson, \#292487). The fecal samples were swabbed directly onto the agar plates and streaked with a heat-sterilized metal loop. Phosphatebuffered saline was added to the fecal collection tubes to create a fecal slurry which was then used to inoculate Bolton Broth media. If bacterial growth was insufficient on direct fecal plating, the Bolton Broth culture was inoculated on to the selective plate media. A strain of C. jejuni (ATCC 33291), was cultured at the same time to serve as a positive control.

The plates were incubated in one of two containers: hard, air-fast canisters for more than two plates, with an Anaeropack-MicroAero pack (Mitsubishi Gas Chemical Co., Inc., Tokyo, Japan), or in groups of two plates in BioBag Type Cfj bags (Becton Dickinson, \#261212); incubation was done at a temperature of $40^{\circ} \mathrm{C}$ for 2 days under microaerophilic conditions, after which the cultures were removed, plates described, and suspect colonies transferred to new agar plates. Preliminary confirmation for Campylobacter spp. was achieved with a combination of Gram stain, catalase, and oxidase tests, while real-time polymerase chain or matrix-associated laser desorption ionization mass spectrometry (MALDI-TOF, Bruker Bioytper Compass, Billerica, MA, USA) analysis were used for definitive confirmation of cultured Campylobacter and their species. ${ }^{19}$ For the samples analyzed by matrix-associated laser desorption ionization mass spectroscopy, a log score was generated based on the peaks obtained from the sample and the comparison of the obtained data against a library of bacterial standards. A positive result was reported if the log score was greater than or equal to 2.000 (on a scale of 0.000-3.000) indicative of an acceptable probability of sample classification at the species level.

\section{Results and discussion}

Of the 26 chicken fecal samples, eight (30\%) were determined to contain C. jejuni. All 27 psittacine-derived samples were negative. These negative birds included an African Gray (Psittacus erythracus) (ID\# R2786) and a Great Green Macaw (Ara ambigua)(ID\#. 229721), both of which were previously diagnosed as suffering from PDD and were shedding PaBV in their droppings at the time of sampling. Additionally, none of the four parrots admitted to the Texas A\&M veterinary clinic on suspicion of PDD were Campylobacter positive. (One macaw, one African gray, one Amazona sp, and a sulfur-crested cockatoo). Additionally, it should be pointed out that the cockatiels housed in the aviary belonged to a flock that had been shown repeatedly to be consistently susceptible to developing typical PDD upon challenge with PaBV-1, genotype 2 .

Campylobacter is present in many wild birds including pigeons, waterfowl, starlings, and corvids. ${ }^{13,14,20,21}$ There has been but a single report of Campylobacter in parrots; during a disease outbreak in Peru. ${ }^{22}$ We have investigated the normal gut microbiota of wild and captive scarlet macaws and failed to detect Campylobacter. ${ }^{23}$ Likewise, Campylobacter has not 
been detected in the normal microbiota of the cockatiel. ${ }^{24}$ Conversely, Campylobacter species, especially C. jejuni, are pervasive in chicken gut flora. ${ }^{18}$ Our poultry sample contained Campylobacter as expected, and thus served as a positive control. The absence of Campylobacter in psittacine samples suggests that colonization by this bacterium may infrequent in these species.

Rossi et $a l^{8}$ have postulated that PDD is not exclusively caused by PaBV infection and that some cases may be induced by Campylobacter, particularly C. jejuni. The number of confirmed PDD cases analyzed here is insufficient to rule out Campylobacter infection as a cause or contributing factor to PDD. However, we can induce PDD at-will in cockatiels by inoculation of PaBV-1 genotype 2, and as described above, our cockatiel flock appears to be free of Campylobacter. GBS can be induced in poultry but its manifestations in no way resemble PDD. They are primarily abnormalities in motor behavior. ${ }^{25}$ It has long been known that Borna disease in rodents is mediated by activated T-cells directed against infected neurons expressing bornaviral $\mathrm{N}$ protein..$^{26}$ It is probable that the situation in birds is the same, and so we suggest that $C$. jejuni does not play a significant role in the pathogenesis of PDD.

\section{Disclosure}

The authors report no conflicts of interest in this work.

\section{References}

1. Hoppes SM, Gray PL, Payne SL, Shivaprasad HL, Tizard I. The isolation, pathogenesis, diagnosis, transmission, and control of avian bornavirus and proventricular dilatation disease. Vet Clin North Am Exot Anim Pract. 2010;13(3):495-508.

2. Tizard IR, Shivaprasad HL, Guo J, Hameed S, Ball J, Payne S. The pathogenesis of proventricular dilatation disease. Anim Health Res Rev. 2016;17(2):110-126.

3. Rubbenstroth D, Rinder M, Stein M, et al. Avian bornaviruses are widely distributed in canary birds. Vet Microbiol. 2013;165:287-295.

4. Delnatte P, Ojkic D, Delay J, Campbell D, Crawshaw G, Smith DA. Pathology and diagnosis of avian bornavirus infection in wild Canada geese (Branta canadensis), trumpeter swans (Cygnus buccinator) and mute swans (Cygnus olor) in Canada: a retrospective study. Avian Pathol. 2013;42:114-128.

5. Mirhosseini N, Gray PL, Hoppes S, Tizard I, Shivaprasad HL, Payne S. Proventricular dilatation disease in cockatiels (Nymphicus hollandicus) after infection with a genotype 2 avian bornavirus. J Avian Med Surg. 2011;25(3):199-204

6. Piepenbring AK, Enderlein D, Herzog S, et al. Pathogenesis of avian bornavirus in experimentally infected cockatiels. Emerg Infect Dis. 2012;18(2):234-241.

7. Rossi G, Crosta L, Pesaro S. Parrot proventricular dilation disease. Vet Rec. 2008;163(10):310.
8. Rossi G, Galosi L, Ceccherelli R, Piccinini A, Orosz SE, Pesaro S. Parrot's PDD Is a Multifactorial Disease? New Pathogenetic Evidences for an Auto-Immune Ganglioneuritis. XXIV Congreso Panamericano De Ciencias Veterinarias. La Habana, Cuba: Panvet; 2014.

9. Jasti AK, Selmi C, Sarmiento-Monroy JC, Vega DA, Anaya JM, Gershwin ME. Guillain-Barre syndrome: causes, immunopathogenic mechanisms and treatment. Expert Rev Clin Immunol. 2016;12(11): 1175-1189.

10. St Charles JL, Bell JA, Gadsden BJ, et al. Guillain Barre Syndrome is induced in Non-Obese Diabetic (NOD) mice following Campylobacter jejuni infection and is exacerbated by antibiotics. J Autoimmun. 2017;77:11-38.

11. Zhang M, Gilbert M, Yuki N, et al. Association of anti-GT1a antibodies with an outbreak of Guillain-Barre Syndrome and analysis of ganglioside mimicry in an associated Campylobacter jejuni strain. PLoS One. 2015;10(7):e0131730.

12. Griekspoor P, Colles FM, McCarthy ND, et al. Marked host specificity and lack of phylogeographic population structure of Campylobacter jejuni in wild birds. Mol Ecol. 2013;22(5):1463-1472.

13. Mohan V. Faeco-prevalence of Campylobacter jejuni in urban wild birds and pets in New Zealand. BMC Res Notes. 2015;8:1.

14. Ramonaite S, Novoslavskij A, Zakariene G, et al. High prevalence and genetic diversity of Campylobacter jejuni in wild crows and pigeons. Curr Microbiol. 2015;71(5):559-565.

15. Dudzic A, Urban-Chmiel D, Stepien-Pysniak M, et al. Isolation, identification and antibiotic resistance of Campylobacter strains isolated from domestic and free-living pigeons. Br Poult Sci. 2016;57(2):172-178.

16. Taff CC, Weis AM, Wheeler S, et al. Influence of host ecology and behavior on Campylobacter jejuni prevalence and environmental contamination risk in a synanthropic wild bird species. Appl Environ Microbiol. 2016;82(15):4811-4820.

17. Konicek C, Vodrazka P, Bartak P, et al. Detection of zoonotic pathogens in wild birds in the cross-border region Austria - Czech Republic. J Wildl Dis. 2016;52(4):850-861.

18. Sahin O, Kassem II, Shen Z, et al. Campylobacter in poultry: ecology and potential interventions. Avian Dis. 2015;59(2):185-200.

19. Muhamadali H, Weaver D, Subaihi A, et al. Chicken, beams, and Campylobacter: rapid differentiation of foodborne bacteria via vibrational spectroscopy and MALDI-mass spectrometry. Analyst. 2016;141(1): 111-122.

20. Weis AM, Miller WA, Byrne BA, et al. Prevalence and pathogenic potential of Campylobacter isolates from free-living, human-commensal american crows. Appl Environ Microbiol. 2014;80(5):1639-1644.

21. Cody AJ, McCarthy ND, Bray JE, et al. Wild bird-associated Campylobacter jejuni isolates are a consistent source of human disease, in Oxfordshire, United Kingdom. Environ Microbiol Rep. 2015;7(5): $782-788$.

22. Tresierra-Ayala A, Bendayan ME. Thermotolerant Campylobacter species isolated from psittaciformes in the Peruvian Amazon region. Rev Inst Med Trop Sao Paulo. 1998;40(4):263-264.

23. Xenoulis PG, Gray PL, Brightsmith D, et al. Molecular characterization of the cloacal microbiota of wild and captive parrots. Vet Microbiol. 2010;146(3-4):320-325.

24. Alcaraz LD, Hernandez AM, Peimbert M. Exploring the cockatiel (Nymphicus hollandicus) fecal microbiome, bacterial inhabitants of a worldwide pet. Peer J. 2016;4:e2837.

25. Leall de Araujo J, Tizard I, Guo J, et al. Are anti-ganglioside antibodies associated with proventricular dilatation disease in birds? Peer J. 2017.

26. Furrer E, Bilzer T, Stitz L, Planz O. High-dose Borna disease virus infection induces a nucleoprotein-specific cytotoxic T-lymphocyte response and prevention of immunopathology. J Virol. 2001;75:11700-11708. 
Veterinary Medicine: Research and Reports is an international, peer-reviewed, open access journal publishing original research, case reports, editorials, reviews and commentaries on all areas of veterinary medicine. The manuscript management system is completely online and includes a very quick and fair peer-review system.
Visit http://www.dovepress.com/testimonials.php to read real quotes from published authors.

Submit your manuscript here: http://www.dovepress.com/veterinary-medicine-research-and-reports-journal 